\title{
On a certain subclass of analytic functions defined by a generalized Sălăgean operator and Ruscheweyh derivative
}

\section{Alina Alb LUPAŞ}

\section{ABSTRACT.}

In the present paper we define a new operator using the generalized Sălăgean and Ruscheweyh operators. Denote by $R D_{\lambda, \alpha}^{m}$ the operator given by $R D_{\lambda, \alpha}^{m}: \mathcal{A}_{n} \rightarrow \mathcal{A}_{n}, R D_{\lambda, \alpha}^{m} f(z)=(1-\alpha) R^{m} f(z)+\alpha D_{\lambda}^{m} f(z), z \in U$, where $R^{m} f(z)$ denote the Ruscheweyh derivative, $D_{\lambda}^{m} f(z)$ is the generalized Sălăgean operator and $\mathcal{A}_{n}=\left\{f \in \mathcal{H}(U): f(z)=z+a_{n+1} z^{n+1}+\ldots, z \in U\right\}$ is the class of normalized analytic functions. A certain subclass, denoted by $\mathcal{R D}_{m}(\delta, \lambda, \alpha)$, of analytic functions in the open unit disc is introduced by means of the new operator. By making use of the concept of differential subordination we will derive various properties and characteristics of the class $\mathcal{R} \mathcal{D}_{m}(\delta, \lambda, \alpha)$. Also, several differential subordinations are established regarding the operator $R D_{\lambda, \alpha}^{m}$.

Department of MATHEMATics ANd COMPUter SCIENCE

UNIVERSITY OF ORADEA

UNIVERSITATII 1, 410087 ORADEA, ROMANIA

E-mail address: dalbeuoradea.ro 